\title{
Penerapan Metode Simple Additive Weighting Untuk Perangkingan Kinerja Pegawai Terbaik di STIKes Getsempena Lhoksukon
}

\author{
Mukhroji ${ }^{a}$ Fadhlina ${ }^{b}$ \\ ${ }^{a}$ STIKes Getsempena Lhoksukon, Jalan Medan Banda Aceh KM 292 Simpang Dama, Aceh Utara, Indonesia \\ ${ }^{b}$ STIKes Getsempena Lhoksukon, Jalan Medan Banda Aceh KM 292 Simpang Dama, Aceh Utara, Indonesia
}

\section{INFORMASIARTIKEL}

\section{Sejarah Artikel:}

DiterimaRedaksi: 10 Nov 2020

RevisiAkhir: 15 April 2021

DiterbitkanOnline: 30 April 2021

\section{KATA KUNCI}

Performance, SAW, criteria, attribute

\section{KORESPONDENSI}

E-mail: roeji5990@gmail.com

\begin{abstract}
A $\quad$ B $\mathbf{S} \quad \mathbf{T} \quad \mathbf{R}$ A $\mathbf{C}$ T
Employee performance appraisal in an institution is an absolute thing that needs to be done, where employees compete fiercely to get the best category in order to achieve a brilliant career in that agency. Every agency needs qualified, honest, educated, and disciplined employees to ensure good quality. Each agency has a different and selective way of determining good employees, this can also be a consideration for agency leaders to choose the best employee criteria so that they are worthy of being placed in strategic positions. From some of the descriptions above, this research needs to be carried out which aims to assist a leader in an institution in determining the best employees. This study applies the Simple Additive Weighting (SAW) method for decision making to rank the best employee performance. The steps taken are determining the criteria and attributes that will be the reference in the decision matrix assessment so that the final result obtained is the ranking of the best criteria and attribute values that can help the leadership of an agency to make informed decisions in determining the best employees to be placed in strategic positions in these agencies.
\end{abstract}

\section{PENDAHULUAN}

Didalam sebuah instansi, salah satu elemen yang sangat perlu diperhatikan adalah Sumber Daya Manusia (SDM). Pengelolaan SDM yang baik sangat mempengaruhi sebuah keberhasilan kinerja seorang pegawai dalam pencapaian target yang diberikan oleh instansi. Sistem dalam sebuah instansi dapat berjalan dengan baik apabila SDM nya dapat diorganisir dengan baik pula.

Pada dasarnya, proses Multiple Attribute Decision Making (MADM ) dapat dilakukan melalui beberapa tahap diantaranya penyusunan komponen kondisi, analisis serta sintesis sistem informasi. Ada beberapa metode yang dapat digunakan untuk menyelesaikan masalah MADM antara lain sebagai berikut [2]: Simple Additive Weighting (SAW), Weighting Product (WP), ELECTRE, Technique for Order Preference by Similarity to Ideal Solution (TOPSIS), Analytic Hierarchy Process (AHP). Simple Additive Weighting (SAW) merupakan salah satu metode yang dapat digunakan untuk penentuan sistem pengambilan keputusan. Pada penelitian terkait [3] penerapan metode SAW dilakukan dalam penilaian kinerja dosen. Hasil dari penelitian ini dapat memberikan rekomendasi dan pertimbangan serta dapat mengurangi tingkat kesalahan dalam merekrut dosen pada sebuah perguruan tinggi melalui perangkingan.

Penelitian terkait [4] memformulasikan perhitungan aplikasi pendukung keputusan pada beasiswa penelitian RISPRO dengan menggunakan metode SAW. Nilai akhir yang digunakan sebagai bahan acuan pengambilan keputusan, memiliki selisih yang sedikit untuk kemudian diurutkan, sehingga pengambil keputusan dapat mengambil data beberapa peserta dengan nilai yang tinggi.

\section{TINJAUAN PUSTAKA}

\subsection{Simple Additive Weighting (SAW)}

Dari hasil perhitungan yang didapat, penggunaan metode ini memungkinkan pengolahan data yang lebih tepat, cepat dan akurat serta dapat memberikan rekomendasi calon peserta yang layak menerima beasiswa penelitian. Menurut Subandi Wahyudi [5] dalam penelitian nya menyatakan bahwa metode Simple Additive Weighting (SAW) yang diterapkan dalam aplikasi dapat menghitung dan memberikan hasil akhir penilaian yang telah dirangkingkan sehingga dapat menentukan karyawan kontrak menjadi karyawan tetap dengan tepat. Dengan Sistem Pendukung Keputusan (SPK) yang dikembangkan 
menggunakan Multiple Attribute Decision Making (MADM) dengan metode Simple Additive Weighting (SAW) dalam penentuan prioritas ini dapat mengefektifkan pengambilan keputusan yang dilakukan oleh pengambil keputusan, karena nilai setiap kriteria pada proses penentuan prioritas yang dilakukan menggunakan metode SAW telah ditentukan, sehingga proses penilaian akan lebih tepat karena didasarkan pada nilai kriteria dan bobot yang telah ditentukan. Metode Simple Additive Weighting ini akan menghasilkan alternatif terbaik dari sejumlah alternatif yang diberikan[6]

Salah satu tujuan STIKes Getsempena melakukan penilaian terhadap pegawai terbaik adalah agar dapat meningkatkan semangat kinerja pegawai dalam mencapai target yang telah ditentukan. Penilaian pegawai terbaik sudah dilakukan namun dirasa belum terlalu optimal dalam proses pelaksanaannya di lapangan. Ada beberapa kendala yang dihadapi STIKes Getsempena antara lain pimpinan menilai sebuah kinerja tanpa menggunakan metode sehingga sulit untuk menilai pegawai yang akan di preoritaskan serta cara penilaian pada instansi terhadap karyawan masih manual. Kesulitan juga timbul saat pegawai yang akan dinilai terlalu banyak sehingga sulit untuk menentukan banyaknya kriteria penilaian pegawai terbaik.

Oleh karena itu peneliti mengangkat tema penelitian dengan judul "Penerapan Metode Simple Additive Weighting untuk Perangkingan Kinerja Pegawai Terbaik di STIKes Getsempena". Menurut Mahrizal Masri [1] dalam penelitiannya menjelaskan dengan adanya sistem pengambilan keputusan yang dibuat telah membantu mempermudah keputusan Manager perusahaan dalam mendapatkan penentuan karyawan terbaik sesuai dengan kirteria - kriteria yang dibutuhkan oleh tiap - tiap objek penempatan.

Metode pengambilan keputusan yang dipilih dalam penelitian ini adalah Simple Additive Weighting (SAW), karena proses penilaian dalam metode ini adalah menentukan nilai bobot pada setiap atribut sehingga output yang didapat merupakan hasil seleksi alternative terbaik untuk menentukan keputusan. Metode SAW akan diimplementasikan kedalam sebuah aplikasi yang dapat diakses setingkat pimpinan sekolah tinggi, didalam aplikasi akan ada beberapa penilaian terhadap karyawan yang dapat diisi oleh pimpinan sekolah tinggi sehingga dapat merekomendasikan kepada pimpinan nantinya karyawan dengan kinerja terbaik.

\section{METODOLOGI}

Penelitian ini melakukan perangkingan terhadap kinerja pegawai yang terbaik di STIKes Getsempena. Metode yang digunakan pada penelitian ini adalah Sistem Pengambilan Keputusan (SPK) Multipe Attribute Decision Making (MADM) - Simple Additive Weighting (SAW). Tahapan awal pengujian ini adalah mengkaji teori yang relevan dari berbagai sumber reverensi penelitian sejenis yang pernah dilakukan untuk mendapatkan landasan teori mengenai penelitian yang akan dilakukan.

Penyusunan instrument penelitian dilakukan agar penelitian ini terarah terhadap hal apa yang perlu dilakukan ditahap awal sampai tahap akhir sehingga dapat mewujudkan sebuah 2 Mukhroji penerapan metode untuk membuat sistem pengambilan keputusan yang dapat membantu seorang pimpinan isntitusi dalam mengambil sebuah kebijakan penentuan pegawai terbaik, hal ini perlu dilakukan mengingat seorang pegawai yang memenuhi kriteria sebagai pegawai terbaik akan ditetapkan pada jabatan - jabatan strategis dalam isntitusi tersebut.

Adapun tahapan secara garis besar penerapan metode SAW ini adalah penentuan kriteria yang harus ditetapkan, pada penentuan kriteria tidak ada batasan, namun semakin banyak kriteria akan semakin menambah akurasi penilaian dalam pengurutan nilai sebuah alternatif. Penentuan bobot juga harus dilakukan, ada beberapa kriteria penentuan nilai bobot, salah satunya menggunakan logika fuzzy.

Tahapan selanjutnya pembentukan matrik keputusan dari nilai beberapa kriteria yang sudah ditentukan. Setelah mendapat nilai matrik keputusan, tahapan terakhir adalah menghitung normalisasi dari setiap alternatif atau nilai rating kerja ternormalisasi untuk mendapatkan kriteria terbaik pada sebuah alternatif. Berikut adalah bagan alir penelitian menjelaskan tahapan - tahapan yang dilakukan pada penelitian ini yang akan dijelaskan pada gambar berikut.

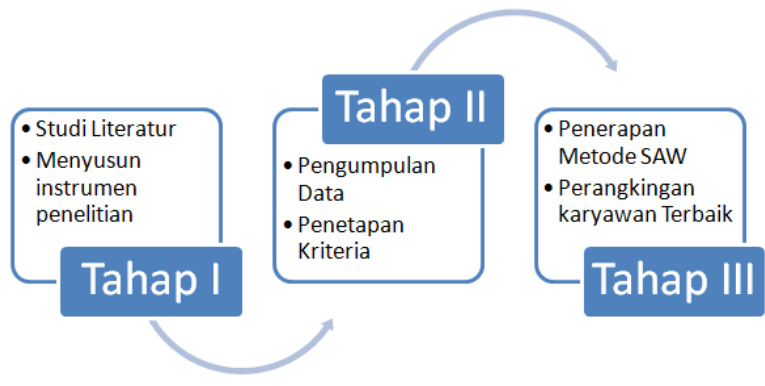

Gambar 1. Tahapan Penelitian

\section{HASIL DAN PEMBAHASAN}

Pada bagian ini akan menjelaskan hasil dari pengolahan data dan analisa berdasarkan metode penelitian yang telah dijelaskan. Pembahasan terfokus pada permasalahan perangkingan kinerja staf terbaik di lingkungan STIKes Getsempena. Hasil daripada penilaian kriteria yang akan diterapkan kedalam metode Simple Additive Weighting (SAW) untuk mendapatkan alternatif terbaik dari penilaian kinerja staf.

\subsection{STIKes Getsempena Lhoksukon}

STIKes Getsempena Lhoksukon merupakan salah satu Perguruan Tinggi Swasta yang berada di area Kabupaten Aceh Utara. STIKes Getsempena memiliki 4 prodi aktif di bidang kesehatan. Memiliki 38 dosen aktif dan 15 dosen menduduki jabatan struktural. STIKes Getsempena berdiri pada tahun 2008 dan sekarang sudah memiliki gedung sendiri diatas tanah seluas 2,4 hektar tepatnya di Desa Ulee Tanoh, Kecamatan Tanah Pasir, Kabupaten Aceh Utara. 


\subsection{Pengujian}

Pengujian dilakukan dengan pendataan beberapa staf, dalam kasus ini diambil 5 sampel. Ada tiga aspek penilaian dalam penelitian ini yang akan diberikan bobot nilai pada setiap aspek. Yang pertama adalah kedisiplinan dalam bekerja, yang kedua adalah kerja sama tim, dan yang ketiga adalah prestasi kerja.

Penelitian terkait pembobotan diberikan antara nilai 0 sampai dengan 1 [7]. Apabila kriterianya ada 4 diasumsikan pembaginya setara (equal) sehingga pembobotan diberikan dari bobot terendah sampai bobot tertinggi yaitu $0,25,0,5,0,75$, dan 1. Dan apabila kriterianya ada 5 , maka pembobotan terendah sampai tertinggi adalah $0,2,0,4,0,6,0,8$, dan 1 . Berdasarkan definisi penelitian diatas, maka pembobotan pada penelitian ini ditentukan berdasarkan aspek penilaian kinerja yang terdapat pada tabel 2 terdapat 3 aspek penilaian.

Tabel 1. Bobot Kriteria

\begin{tabular}{lllll}
\hline Kriteria & C1 & C2 & C3 & C4 \\
\hline Bobot & 0,25 & 0,5 & 0,75 & 1 \\
\hline
\end{tabular}

Data matriks akan melalui tahapan normalisasi dengan mengambil nilai pembagi paling besar pada kolom matriks kemudian dibagi dengan matrik pada kolom tersebut barulah didapatkan hasil normalisasi matrik. Setelah mendapatkan nilai normalisasi matriks, dilakukan pencarian hasil perangkingan kinerja pegawai terbaik menggunakan persamaan 2 yang sudah dijelaskan didalam tahapan - tahapan sebagai berikut.

Tahap 1

Tentukan matriks $\mathrm{X}$ dari hasil pengujian sebagai nilai dari kriteria dan alternatif.

$$
X=\left\{\begin{array}{lll}
4 & 2 & 0 \\
4 & 2 & 1 \\
2 & 1 & 0 \\
8 & 2 & 0 \\
5 & 2 & 0
\end{array}\right\}
$$

Tahap 2

Matriks X dari pengujian kerentanan melalui tahapan normalisasi dengan menggunakan persamaan 3 karena manfaat dari seluruh atribut adalah keuntungan, berikut adalah hasil normalisasi matriks:

$R_{i j}=\frac{x_{i j}}{\max x_{i j}}$

$$
\mathrm{R}_{\mathrm{ij}}=\left\{\begin{array}{lll}
0,5 & 1 & 0 \\
0,5 & 1 & 1 \\
0,25 & 0,5 & 0 \\
1 & 1 & 0 \\
0,6 & 1 & 0
\end{array}\right\}
$$

Tahap 3

Setelah mendapatkan matriks ternormalisasi, tiap baris matrik pada alternatif dikalikan dengan bobot yang telah ditentukan pada Tabel 1 menggunakan persamaan berikut:

$$
\begin{aligned}
& \mathrm{V}_{\mathrm{i}}=\mathrm{W}_{\mathrm{j}} \mathrm{R}_{\mathrm{ij}} \\
& \mathrm{V} 1=(0,5 \times 0.5)+(0.75 \times 1)+(1 \times 0)=1 \\
& \mathbf{V} 2=(\mathbf{0 , 5} \mathbf{5 0 . 5})+(\mathbf{0 . 7 5 \times 1})+(\mathbf{1} \times 1)=\mathbf{2} \\
& \mathrm{V} 3=(0,5 \times 25)+(0.75 \times 0.5)+(1 \times 0)=0.5 \\
& V 4=(0,5 \times 1)+(0.75 \times 1)+(1 \times 0)=1.25 \\
& V 5=(0,5 \times 0.6)+(0.75 \times 1)+(1 \times 0)=1.1
\end{aligned}
$$

Dari hasil pengujian diatas, alternatif kedua menunjukkan nilai tertinggi yang berarti alternatif kedua merupakan pegawai yang paling baik kinerjanya, dan alternatif ketiga menunjukkan nilai terendah yang berarti alternatif ketiga merupakan pegawai dengan rangking terendah dibandingkan kelima alternatif pada pengujian ini.

Tahap 4

Setelah mendapatkan hasil pengujian, selanjutnya data pada hasil pengujian akan dimasukkan ke dalam tabel, tujuannya adalah untuk memudahkan dalam memahami proses penerapan metode SAW. Berikut data hasil pengujian ditampilkan dalam tabel 2 dan tabel 3.

Tabel 2. Data Matrik Pengujian

\begin{tabular}{cccc}
\hline $\begin{array}{c}\text { Kriteria/ } \\
\text { Alternatif }\end{array}$ & Kedisiplinan & Kerjasama & $\begin{array}{c}\text { Prestasi } \\
\text { Kerja }\end{array}$ \\
\hline Pegawai 1 & 4 & 2 & 0 \\
Pegawai 2 & 4 & 2 & 1 \\
Pegawai 3 & 2 & 1 & 0 \\
Pegawai 4 & 8 & 2 & 0 \\
Pegawai 5 & 5 & 2 & 0 \\
\hline
\end{tabular}

Tabel 3. Data Normalisasi Matrik

\begin{tabular}{lccccc}
\hline \multicolumn{7}{c}{ Normalisasi $\left(\mathbf{R}_{\mathrm{ij}}\right)$} & & Hasil $\left(\mathbf{V}_{\mathbf{i}}\right)$ \\
\hline Pegawai -1 & 0 & 0.5 & 1 & 0 & 1 \\
Pegawai - & 0 & 0.5 & 1 & 1 & 2 \\
Pegawai - 3 & 0 & 0.25 & 0.5 & 0 & 0.5 \\
Pegawai - 4 & 0 & 1 & 1 & 0 & 1.25 \\
Pegawai -5 & 0 & 0.62 & 1 & 0 & 1.1 \\
\hline
\end{tabular}

Pada Tabel 3 dijelaskan, nilai pembagi adalah nilai tertinggi yang ada pada matriks hasil pengujian seperti dipaparkan pada 
Tabel 3. Nilai pembagi ini akan dikalikan dengan nilai matriks dari hasil pengujian ini disebut dengan normalisasi matriks. Hasil normalisasi matriks akan dikalikan dengan setiap bobot yang dimikiki oleh kriteria, yang sudah dijelaskan pada Tabel 1. Hasil dari perkalian tersebut akan dijumlahkan sehingga didapatkan nilai alternatif terbaik sebagai perbandingan.

\section{KESIMPULAN DAN SARAN}

Dari penelitian dan hasil pengujian yang telah dilakukan, maka dapat disimpulkan bahwa penerapan metode SAW pada penilaian kinerja pegawai di STIKes Getsempena Lhoksukon telah berhasil dilakukan dan dapat diambil keputusan pegawai terbaik dengan pengurutan nilai matrik ternormalisasi. Penerapan metode SAW ini diharapkan dapat dirancang kedalam aplikasi berbasis website sehingga dapat memudahkan seorang pimpinan nantinya dalam mengambil keputusan untuk penilaian kinerja pegawai terbaik.

\section{DAFTAR PUSTAKA}

Daftar Pustaka dapat di ambildaribukuataujurnaldanditulis mengikuti formatIEEE style berikut:

[1] Mahrizal Masri. "Penentuan Karyawan Terbaik Dengan Metode Simple Additive Weighting (PDAM Titra Silaupiasa)", Jurnal of Electrical Technology Vol 1, No 1, 2016

[2] Heri Sismoro, Hartatik, "Multiple Attribute Decision Making - Penggunaan Metode SAW dan WPM Dalam Pemilihan Proposal UMKM", Jurnal DASI Vol.14 No.1, STMIK AMIKOM Yogyakarta, 2015

[3] Agus Faizin, Edy Mulyanto, "Penerapan Metode Simple Additive Weighting (SAW) Untuk Seleksi Tenaga Kerja Baru Bagian Produksi”, Information Engineering and Electronic Business 2015.

[4] Rahman Abdilah, "Implementasi Fuzzy Simple Additive Weighting (SAW) Sebagai Pendukung Keputusan Pada Beasiswa Penelitian", Jurnal String Vol. 2 No. 1, 2017.

[5] Sabandi Wahyudi, Heri Suheri, Thoha Nurhadian, "Implementasi Sistem Keputusan Pengangkatan Karyawan Tetap PT. Imanuel Surya Utama Menggunakan Metode SAW”, Jurnal PROSISKO Vol. 2 No. 1, 2015.

[6] Y. Utama, "Sistem Pendukung Keputusan untuk Menentukan Prioritas Penanganan Perbaikan Jalan Menggunakan Metode SAW Berbasis Mobile Web", Jurnal Sistem Informasi (JSI), Vol 5, No 1, pp. 566-584, Apr. 2013

[7] Dian Novita Handayani, Fitro Nur Hakim, Achmad Solechan., 2014. Sistem Pendukung Keputusan untuk Pemilihan Jurusan Menggunakan Fuzzy Multiple Atribute Decision Making dengan Metode SAW Studi Kasus Pada SMA Islam Sultan Agung 1. JurnalTransformatika. Vol 11 no 2.2014

\section{BIODATA PENULIS}

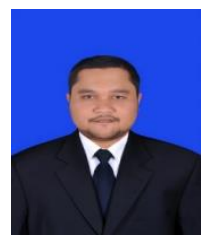

Penulis Pertama

Mukhroji, SST.,MT. merupakan dosen tetap di STIKes Getsempena Lhoksukon Aceh Utara. Menyelesaian studi Diploma 4 di Politeknik Negeri Lhokseumawe dan Studi Strata 2 di Univ. Syiah Kuala Banda Aceh.

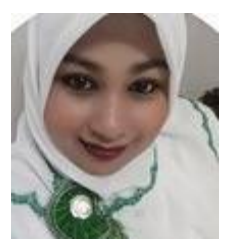

\section{Penulis Kedua}

Ns. Fadhlina, S.Kep., M.KM merupakan dosen tetap di STIKes Getsempena Lhoksukon. 